\title{
Erratum to: Readmission rates of South Korean psychiatric inpatients by inpatient volumes per psychiatrist
}

\author{
Kyu-Tae Han ${ }^{1,2}$, Seo Yoon Lee ${ }^{2,3}$, Sun Jung Kim ${ }^{4}$, Myung-II Hahm ${ }^{4}$, Sung-In Jang ${ }^{1,2,5}$, Seung Ju Kim,2, \\ Woorim Kim ${ }^{1,2}$ and Eun-Cheol Park ${ }^{2,5^{*}}$
}

\section{Erratum}

Following publication of the original article in $B M C$ Psychiatry [1], it was brought to our attention that the results and conclusions sections in the abstract are incorrect:

The results section in the abstract should read:

Readmissions within 30 days accounted for 1,598 $(4.5 \%)$ claims. Multilevel analysis demonstrated that inpatient volume per psychiatrist were positively related with readmission within 30 days (low odds ratio [OR]: 0.38, $95 \%$ confidence interval [CI]: 0.28-0.51; mid-low OR: 0.48, 95 \% CI: 0.36-0.63; mid-high OR: 0.55, $95 \%$ CI: 0.44-0.69; Q4= ref). The subgroup analysis by diagnosis revealed that both "schizophrenia, schizotypal, and delusional disorders" and "mood disorders" had positive relationships with readmission risk for all volume groups.

The conclusions section in the abstract should read: We observed a positive association between inpatient volume per psychiatrist and the 30-day readmission rate of psychiatric inpatients, suggesting that it could be a useful quality indicator in mental health care.

We apologize for the inconvenience this may have caused.

\begin{abstract}
Author details
'Department of Public Health, Graduate School, Yonsei University, Seoul, Republic of Korea. ${ }^{2}$ Institute of Health Services Research, Yonsei University College of Medicine, Seoul, Republic of Korea. ${ }^{3}$ Department of Health Policy and Management, Graduate School of Public Health, Yonsei University, Seoul, Republic of Korea. ${ }^{4}$ Department of Health Administration and Management, Soonchunhyang University, Asan, Republic of Korea. ${ }^{5}$ Department of Preventive Medicine, Yonsei University College of Medicine, 50 Yonsei-ro, Seodaemun-gu, Seoul 120-752, Republic of Korea.
\end{abstract}

* Correspondence: ecpark@yuhs.ac

${ }^{2}$ Institute of Health Services Research, Yonsei University College of Medicine, Seoul, Republic of Korea

${ }^{5}$ Department of Preventive Medicine, Yonsei University College of Medicine, 50 Yonsei-ro, Seodaemun-gu, Seoul 120-752, Republic of Korea
Received: 4 May 2016 Accepted: 11 May 2016

Published online: 27 June 2016

\section{Reference}

1. Han KT et al. Readmission rates of South Korean psychiatric inpatients by inpatient volumes per psychiatrist. BMC Psychiatry. 2016;16:96.
Submit your next manuscript to BioMed Central and we will help you at every step:

- We accept pre-submission inquiries

- Our selector tool helps you to find the most relevant journal

- We provide round the clock customer support

- Convenient online submission

- Thorough peer review

- Inclusion in PubMed and all major indexing services

- Maximum visibility for your research

Submit your manuscript at www.biomedcentral.com/submit 